\title{
La Vigilancia de los Viruses Acarreados por Mosquitos ${ }^{1}$
}

\author{
Jorge R. Rey y C. Roxanne Rutledge ${ }^{2}$
}

\section{Los Mosquitos y la Transmisión de Enfermedades en Florida}

Existen tres importantes enfermedades acarreadas por mosquitos en Florida: La encefalitis equina oriental, la encefalitis de St. Louis, y la fiebre/encefalitis del Nilo Occidental. Todas estas enfermedades son causadas por viruses que son transmitidos por la picada de mosquitos infectados.

Las hembras adultas de los mosquitos se alimentan de sangre para obtener suficientes nutrientes para poder desarrollar sus huevos. Si el mosquito se alimenta de un ave que está infectada con uno de los viruses es posible que el mosquito obtenga el virus de la sangre del ave. Al paso de una o dos semanas, si el virus ha sobrevivido en el mosquito y se ha multiplicado suficientemente, el mosquito puede infectar a otras aves o a otros hospederos, por ejemplo, a humanos o caballos. Cuando los mosquitos se alimentan de sangre, ellos producen saliva, en la cual se puede transmitir el virus. Si el virus infecta a un humano o a un caballo, existe la posibilidad de que este se enferme y desarrolle síntomas de encefalitis. Más a menudo, sin embargo, los hospederos no demuestran ningún síntoma de la enfermedad, o solo desarrollan síntomas leves, como dolores de cabeza de poca intensidad. Estos hospederos desarrollan anticuerpos contra la enfermedad luego de ser infectados por primera vez. Muchas aves puede hospedar al virus sin que les cause daño, pero el virus de Nilo Occidental es fatal para muchas especies de córvidos y raptores (azulejos, cuervos, halcones, etc.).

\section{El Control de Mosquitos en Florida}

Desde principios de siglo XX, distritos para el control de mosquitos han operado en Florida para proteger al público de las fastidiosas picadas de mosquitos y de las enfermedades acarreadas por ellos. En el año 2003 existían más de 50 distritos de control de mosquitos en Florida. Uno de los componentes más importantes de cualquier programa para el control de los mosquitos es la vigilancia.

Un programa de vigilancia integrado debe vigilar las condiciones meteorolgicas, la abundancia de los

1. Este documento con la identificación: ENY-699S, es uno de una serie de publicaciones del Departamento de Entomología y Nematología, del Servicio de Extensión Cooperativo de la Florida, del Instituto de Alimentos y Ciencias Agrícolas, universidad de la Florida. Publicado por primera vez en agosto, 2004. Por favor, visite la dirección en la Red EDIS en 〈http://edis.ifas.ufl.edu〉.

2. Jorge R. Rey, Professor, C. Roxanne Rutledge, Assistant Professor, Florida Medical Entomology Laboratory, Vero Beach, FL; Entomology and Nematology Department, Cooperative Extension Service, Institute of Food and Agricultural Sciences, University of Florida, Gainesville, 32611. El uso de nombres comerciales que han sido mencionados en esta publicación fue únicamente con el propósito de proporcionar información específica. El hecho de nombrar estos productos por UF/IFAS, no es una garantía o garantiza que sean los más efectivos en el mercado, y no significa que son avalados por la institución y que otros compuestos similares deben ser excluidos.

Utilize los insecticidas con seguridad. Léa y siga las instrucciones que provee el fabricante en la etiqueta. 
mosquitos, la abundancia de hospederos, la actividad viral, los casos humanos de enfermedades transmitidas por mosquitos, y otras variable usadas para detectar y predecir cambios en la dinámica de transmisión de los viruses acarreados por los mosquitos (CDC 1993). Este documento trata sobre la vigilancia de la actividad de los viruses, esto es, la vigilancia de los organismos que pueden ser transmitidos por los mosquitos de un hospedero a otro.

\section{Herramientas para la Vigilancia}

Existen varias herramientas que han sido desarrolladas para la vigilancia de los viruses acarreados por mosquitos. Algunas incorporan a los mosquitos, mientras que otras utilizan hospederos, por ejemplo, aves, caballos o humanos. Lo que sigue es una descripción de las herramientas disponibles a los distritos de control de mosquitos o a los departamentos de salud pública para la vigilancia de los viruses acarreados por mosquitos. La Tabla 1 indica las ventajas y desventajas de cada una desde el punto de vista de un programa operacional de control de mosquitos.

\section{Vigilancia de Pollos Sentinelas}

Grupo de pollos se ubican en sitios estratégicos y seguros, donde son expuestos a picadas de mosquitos. Muestras de sangre son extraídas semanalmente y son enviadas al Departamento de Salud del Estado. Los animales se mantienen en un solo sitio, y las muestras de sangre son obtenidas dentro de un horario fijo. Parte de los resultados están listos en una semana, la otra parte en dos semanas. El muestreo es activo, ya que no depende de reportes de otras personas, y no depende de reportes ocasionales del público. Un pollo positivo prueba que existe transmisión local reciente, y se puede calcular el momento de infección con bastante precisión.

\section{Vigilancia de Caballos}

Un caballo se enferma y se avisa al veterinario. El veterinario obtiene muestras de sangre o de tejidos del caballo y las envía al Departamento de Salud de Florida y al Laboratorio Nacional de Servicios Veterinarios en Ames, Iowa. El muestreo es pasivo, ya que depende de que caballos enfermos sean reportados a veterinarios, y luego a la División de Animales del Departamento de Agricultura de Florida.. Pueden pasar de cuatro a seis semanas antes de que las agencias de control de mosquitos sean notificadas de que un caballo resultó positivo. Si el caballo positivo no se ha mudado recientemente, entonces ofrece evidencia de transmisión local.

\section{Pruebas en los Mosquitos}

Se hacen colecciones de mosquitos, y los mosquitos se separan, se identifican, y se congelan. Los mosquitos se deben mantener vivos hasta ser congelados. Las pruebas se hacen en grupos que contienen de una a 50 hembras por muestra, lo cual se conoce como pozo de mosquitos. Los mosquitos se deben mantener a una temperatura de $-20^{\circ} \mathrm{C}$ hasta que se efectúen las pruebas.

Se conducen pruebas de reacción de cadenas de polymerasa o de aislamiento de viruses para buscar evidencia de exposición al virus de interés.

Ninguna de estas pruebas es capaz de producir evidencia de que el mosquito puede transmitir el virus; las pruebas solo pueden indicar que el mosquito ha tenido contacto con el virus en el pasado. Este tipo de muestreo requiere una alta inversión de tiempo solo para coleccionar e identificar a los mosquitos. Durante periodos cuando no existe una epidemia, hay muy pocos mosquitos infectados en las poblaciones. Por lo tanto, se requieren muestras con un alto número de mosquitos para poder detectar los pocos que están infectados.

\section{Pruebas del Suero de Aves Silvestres}

Se conducen pruebas repetidamente para los anticuerpos de virus en poblaciones locales de aves silvestres. Se atrapan aves adultas e inmaduras se marcan con bandas en las patas, se extrae una muestra de sangre de cada ave, y las aves se liberan para ser capturadas nuevamente. Se requiere un esfuerzo de muestreo alto, ya que las tasas de re-captura de aves marcadas son muy bajas. El proceso es caro, y se requiere personal entrenado y permisos para la captura de aves. Los anticuerpos pueden persistir en las aves por más de dos años, por lo cual una prueba positiva no significa que el ave fue infectada recientemente, pero aves jóvenes aún 
en el nido que prueben ser seropositivas o positivas para el virus ofrecen evidencia de infección reciente.

\section{Reportes de Aves Muertas*}

La muerte de un ave es reportada por un ciudadano, una agencia de control de mosquitos, o un empleado del departamento de salud. El departamento de salud puede o no recoger o aceptar entrega del cadáver. Dependiendo en su condición, puede que sea posible hacer pruebas en el ave muerta. Si el cuerpo prueba ser positivo para el virus del Nilo Oriental, o para los anticuerpos contra este virus, hay evidencia de que el ave fue expuesta al virus en el pasado y que murió en un lugar determinado. Las pruebas no indican ni donde ni cuando el ave fue infectada. Este método de vigilancia es pasivo, ya que depende en el público para encontrar y reportar aves muertas. El efecto de diferentes esfuerzos en reportar aves muertas es desconocido, y toma varias semanas para obtener los resultados de las pruebas. Este método no ofrece prueba de transmisión local.

*El uso de reportes de aves muertas en la vigilancia para las enfermedades transmitidas por mosquitos es una técnica reciente. Antes de 1999, no existía ningún virus en Los Estados Unidos que causara tanta mortalidad en aves como lo hace el virus de Nilo Occidental. Desde la introducción de este virus a Los Estados Unidos, muchos estados han comenzado a conducir pruebas para el virus en aves muertas.

\section{Reportes de Casos en Humanos}

Casos humanos de encefalitis acarreada por mosquitos son, a menudo, la única indicación de que el virus está circulando en cierta área, particularmente en condados donde no existe otro tipo de vigilancia para estos viruses. Este es un método pasivo que depende en la manifestación de enfermedad en humanos. Puede pasar más de un mes antes de que las agencias de control de mosquitos sean notificadas de casos humanos; y para protección de la privacidad de los pacientes, por lo general no se da información sobre la dirección o las actividades del sujeto. Este método es el menos eficiente, ya que actividades de las agencias de control de mosquitos son obstruidas por la demora en los reportes. Cuando el caso al fin es reportado, los mosquitos infectados probablemente ya no existen.

\section{Consideraciones Sobre las Herramientas de Vigilancia}

Antes de decidir cuales herramientas formarán parte de un programa de vigilancia para los viruses acarreados por mosquitos, se deben considerar las siguientes preguntas:

1. ¿Proveerá el método los datos para el denominador que son necesarios para determinar el riesgo?

Por ejemplo, con un grupo de pollos sentinelas de conocido tamaño podemos determinar el porciento de los pollos infectados durante un periodo de tiempo determinado; 1 pollo infectado de 6 susceptibles $=1 / 6=17 \%$ o 5 de $6=5 / 6=83 \%$. Estos porcentajes pueden ser comparados a los porcentajes históricos de ese u otros sitios.

Por el otro lado, datos para el denominador en programas de vigilancia de aves silvestre son difciles de obtener ya que es casi imposible determinar el número de aves susceptibles en una población libre.

2. ¿Cual es el nivel de esfuerzo de muestreo necesario?

$¿$ Cuantas personas se necesitan para coleccionar los datos? ¿Cuanto tiempo tomará? ¿Es fácil o difícil obtener los datos?

3. ¿Cual es el lapso de tiempo desde que se obtienen los datos hasta que se reciben los resultados?

Si los resultados van a ser utilizados en decisiones operacionales para el control de mosquitos, se necesita un lapso corto. Resultados que requieren de cuatro a seis semanas no proveerán información oportuna para decisiones operacionales de control. 
4. ¿Que significan los resultados? ¿Proveerán los resultados información relevante?

Si los resultados no proveen información relevante al caso, el tiempo y el trabajo han sido desperdiciados. Por ejemplo, si una prueba PCR conducida sobre un grupo de mosquitos resulta positiva, eso no significa que específicos mosquitos pueden transmitir el virus. Una prueba PCR positiva no significa que el mosquito tiene importancia en la transmisión del virus ni que es peligroso para los humanos o animales.

5. ¿Se puede efectuar comparaciones históricas?

Es importante que los programas de vigilancia sean de larga duración y que incluyan el mantenimiento de datos por razones históricas. Si un grupo de pollos sentinelas demuestra una tasa de seroconversión (desarrollo de anticuerpos como resultado de infección por el virus) de $30 \%$, se necesita saber como esta tasa compara con la de años anteriores y con la tasa promedio a través del tiempo. Estos tipos de comparaciones son esenciales para poder diferenciar entre niveles normales de fondo y esos que son mayores que lo normal.

6. ¿Como se utilizarán los datos?

El uso de los datos debe ser decidido al principio del programa. Si los datos van a ser usados para hacer decisiones sobre cuando rociar adulticidas, cuando usar larvicidas, o cuando interrumpir el programa de control, entonces uno debe considerar las preguntas anteriores para decidir si el programa de vigilancia puede proporcionar los datos necesarios de manera oportuna.

\section{Metas de la Vigilancia}

Los programas de vigilancia para los viruses acarreados por mosquitos incluyen metas muy específicas que apoyan las preguntas de los trabajadores en el control de mosquitos. Sin importar cuales herramientas son usadas, el programa debe ser bien planeado, de larga duración, debe incluir datos de fondo e históricos, y debe producir resultados con sentido. El caso no es solo generar números; es imperativo que aquellos efectuando el programa sepan lo que están buscando en los datos, por que lo buscan, y su significado.

\section{Referencias Bibliográficas}

CDC. 1993. Guidelines for Arbovirus Surveillance in the United States. U.S. Department of Health and Human Services. Fort Collins, CO, USA. $83 p$.

Day, J. F. and A. L. Lewis. 1991. An integrated approach to Arboviral Surveillance in Indian River County, Florida. J. Florida Mosq. Control Assoc. 62(2): 46-52. 
Tabla 1. Ventajas y desventajas de cada herramienta de vigilancia, desde el punto de vista de programa operacional de control de mosquitos.

\begin{tabular}{|c|c|c|c|c|c|}
\hline & $\begin{array}{l}\text { Datos para el } \\
\text { denominador }\end{array}$ & $\begin{array}{l}\text { Esfuerzo de } \\
\text { muestreo }\end{array}$ & $\begin{array}{l}\text { Tiempo para recibir } \\
\text { resultados }\end{array}$ & $\begin{array}{l}\text { Significado de } \\
\text { los resultados }\end{array}$ & $\begin{array}{l}\text { Se puede } \\
\text { comparar } \\
\text { a datos } \\
\text { hitóricos? }\end{array}$ \\
\hline $\begin{array}{l}\text { Pollos } \\
\text { Sentinelas }\end{array}$ & Sí & $\begin{array}{l}\text { Limitado en } \\
\text { programas } \\
\text { ya } \\
\text { establecidos }\end{array}$ & 1-2 semanas & $\begin{array}{l}\text { Transmisión } \\
\text { local reciente }\end{array}$ & SI \\
\hline Caballos & Sí & Pasivo & 4-6 semanas & $\begin{array}{l}\text { Transmisión } \\
\text { local reciente si } \\
\text { el caballo no se } \\
\text { ha mudado }\end{array}$ & SI \\
\hline Mosquitos & Sí & Extensivo & $\begin{array}{l}6 \text { semanas o más } \\
\text { (prioridad baja) }\end{array}$ & $\begin{array}{l}\text { Nada en } \\
\text { términos de } \\
\text { transmisión o } \\
\text { de implicar a un } \\
\text { vector; el virus } \\
\text { probablemente } \\
\text { está presente } \\
\text { en el area }\end{array}$ & SI \\
\hline $\begin{array}{l}\text { Aves } \\
\text { Silvestres }\end{array}$ & Sí & $\begin{array}{l}\text { Extensivo } \\
\text { (requiere } \\
\text { permisos) }\end{array}$ & $\begin{array}{l}\text { Sear = } 1 \text { semana } \\
\text { Sangre= } \\
\text { semanas }\end{array}$ & $\begin{array}{l}\text { Depende de la } \\
\text { tasa de } \\
\text { recaptura; } \\
\text { juveniles } \\
\text { positivos } \\
\text { indican } \\
\text { transmisión } \\
\text { reciente }\end{array}$ & NO \\
\hline $\begin{array}{l}\text { Aves } \\
\text { Muertas }\end{array}$ & No & $\begin{array}{l}\text { Pasivo (no } \\
\text { confiable) }\end{array}$ & Semanas o más & $\begin{array}{l}\text { Un ave } \\
\text { infectada con el } \\
\text { virus murió en } \\
\text { el particular } \\
\text { sitio }\end{array}$ & NO \\
\hline Humanos & Sí & Pasivo & 4-6 semanas & $\begin{array}{l}\text { Demasido trade } \\
\text { para hacer } \\
\text { decisiones en } \\
\text { cuanto al control } \\
\text { de mosquitos. } \\
\text { Es probable que } \\
\text { existirieron } \\
\text { mosquitos } \\
\text { infectados, pero } \\
\text { posiblemente } \\
\text { en el pasado }\end{array}$ & SI \\
\hline
\end{tabular}

